Article

\title{
Sustained Low Serum Substance P Levels in Non-Surviving Septic Patients
}

\author{
Leonardo Lorente ${ }^{1, *}$, María M. Martín ${ }^{2}$, Antonia Pérez-Cejas ${ }^{3}$, José Ferreres ${ }^{4}$, \\ Jordi Solé-Violán ${ }^{5}$, Lorenzo Labarta ${ }^{6}$, César Díaz ${ }^{7}$ and Alejandro Jiménez ${ }^{8}$ \\ 1 Intensive Care Unit, Hospital Universitario de Canarias, Ofra, s/n. La Laguna, Tenerife 38320, Spain \\ 2 Intensive Care Unit, Hospital Universitario Nuestra Señora Candelaria, \\ Crta Rosario s/n. Santa Cruz Tenerife 38010, Spain; mar.martinvelasco@gmail.com \\ 3 Laboratory Deparment, Hospital Universitario de Canarias, Ofra, s/n. La Laguna, Tenerife 38320, Spain; \\ aperezcejas@gmail.com \\ 4 Intensive Care Unit, Hospital Clínico Universitario de Valencia, Avda, Blasco Ibáñez n 17-19, \\ Valencia 46004, Spain; ferreresj@gmail.com \\ 5 Intensive Care Unit, Hospital Universitario Dr. Negrín, \\ Barranco de la Ballena s/n. Las Palmas de Gran Canaria 35010, Spain; jsolvio@gobiernodecanarias.org \\ 6 Intensive Care Unit, Hospital San Jorge de Huesca, Avenida Martínez de Velasco n 36, Huesca 22004, Spain; \\ llabarta@salud.aragon.es \\ 7 Intensive Care Unit, Hospital Insular, Plaza Dr. Pasteur s/n. Las Palmas de Gran Canaria 35016, Spain; \\ incaicos@yahoo.es \\ 8 Research Unit, Hospital Universitario de Canarias, Ofra, s/n. La Laguna, Tenerife 38320, Spain; \\ ajimenezsosa@gmail.com \\ * Correspondence: lorentemartin@msn.com; Tel.: +34-922678000; Fax: +34-922647112
}

Received: 29 May 2017; Accepted: 13 July 2017; Published: 15 July 2017

\begin{abstract}
Previously, researchers found higher serum substance P (SP) concentrations in survivors of severe sepsis than in non-survivors at the time of severe sepsis diagnosis. The objectives of our current study were to determine whether there is an association between serum SP levels during the first week and sepsis mortality, sepsis severity, serum levels of tumor necrosis factor (TNF)- $\alpha$ and interleukin (IL)-10, and whether serum SP levels during the first week could be used as a biomarker of sepsis mortality. We determined serum concentration of SP, TNF- $\alpha$, and IL-10 at days 1, 4, and 8. The end-point of the study was mortality at 30 days. We found that non-survivor $(n=104)$ compared to survivor patients $(n=206)$ showed lower serum SP levels at days 1,4 , and $8(p<0.001)$. Multiple logistic regression analyses showed an association between 30-day mortality and serum SP levels at days 1,4 , and $8(p<0.001)$ controlling for SOFA score, diabetes mellitus, age, and lactic acid levels. The most interesting findings of our study were that there is an association between serum SP levels during the first week and sepsis mortality, and that serum SP levels during the first week could be used as a biomarker of sepsis mortality.
\end{abstract}

Keywords: substance P; patients; sepsis; mortality; outcome

\section{Introduction}

Sepsis carries a large number of deaths and health care costs annually [1,2]. Tachykinin family includes substance P (SP), neurokinin A (NKA), neurokinin B (NKB), and endokinins [3-12]. Tachykinins are present in the peripheral and central nervous systems, respiratory system, urinary system, immune system, gut, and blood vessels. Tachykinins are involved in different biological processes, such as transmission of nociceptive responses, airway contraction, salivary secretion, smooth muscle contraction, inflammation, vasodilatation, and plasma protein extravasation. SP is involved in 
different diseases, such as asthma, psoriasis, inflammatory bowel disease, anxiety, migraine, psychosis, and central and peripheral nervous systems injury [3-12].

$\mathrm{SP}$ is a polypeptide that is encoded by TAC1 gene, and its effects are mediated binding to $\mathrm{NK}_{1}$ receptor $\left(\mathrm{NK}_{1} \mathrm{R}\right)$ (which is widely expressed in many tissues and cells) [3-12]. SP is considered one of the major initiators of neurogenic inflammation.

The role of SP in sepsis remains unclear. On the one hand, in some studies it was found that SP could play a role in the inflammatory response to sepsis by the release of pro-inflammatory cytokines as interleukin (IL)-1, IL-6, and tumor necrosis factor (TNF)- $\alpha$ [13-16]. On the other hand, in other studies it was found that SP could have anti-inflammatory effects by reducing TNF- $\alpha$, IL-6, and inducible nitric oxide synthase (iNOS), and increasing IL-10 [17,18]. Besides, according to the findings of another studies, SP could play a role in the microorganism clearance modulating the phagocytosis capacity [19-22].

Circulating SP concentrations in septic patients have not been well studied [23-26]. In one study with 61 septic patients, authors found higher serum SP concentrations in septic patients compared to healthy controls, and in non-survivor compared to survivor patients during the final phase of sepsis [23]. In another study with 42 septic patients were found lower plasma SP concentrations in septic patients compared to healthy controls [24]. Other authors have shown an $80 \%$ reduction in SP expression in myenteric plexus neurons of small bowel from patients with peritonitis compared to patients without peritonitis [25]. Our team has determined serum SP levels at the time of severe sepsis diagnosis in 238 severe septic patients [26], and we found higher serum SP concentrations in survivor than in non-survivor severe septic patients. We also found that serum SP concentrations at baseline were associated with 30-day mortality. The objectives of our current research (increasing the sample size to 310 severe septic patients, and determining serum SP levels at days 1, 4, and 8 of severe sepsis diagnosis) were to determine whether there is an association between serum SP levels during the first week and sepsis mortality, sepsis severity, serum levels of TNF- $\alpha$ and IL-10 (as pro-inflammatory and anti-inflammatory cytokine, respectively), and whether serum SP levels during the first week could be used as a biomarker of sepsis mortality. The interest of our current study lies in that if these associations are find, then serum SP levels determination could be used in clinical practice to estimate the prognosis of these patients, and one new approach in the research for the treatment of these patients could be suggested.

\section{Results}

Comparisons on demographic and clinical characteristics between non-survivor $(n=104)$ and survivor severe septic patients $(n=206)$ at moment of severe sepsis diagnosis are showed in Table 1 . We did not find statistically significant differences between non-survivor and survivor severe septic patients on sex, COPD, chronic renal failure, ischemic heart disease, $\mathrm{PaO}_{2} / \mathrm{FIO}_{2}$ ratio, leukocytes, bilirubin, bloodstream infection, site of infection, microorganism responsible of the infection, and serum levels of TNF- $\alpha$. However, we found that non-survivors with severe sepsis compared to survivors had lower platelet count, and higher age, SOFA score, lactic acid, INR, creatinine, aPTT, APACHE-II score, serum IL-10 levels, and rate of diabetes mellitus. In addition, non-survivors had lower serum levels of $\mathrm{SP}$ at the time of severe sepsis diagnosis $(p<0.001)$.

Table 2 compares changes in serum levels of SP, TNF- $\alpha$ and IL-10, and SOFA score during the first week of severe sepsis. Non-survivors in respect to survivors showed lower serum levels of SP (Figure 1), and higher SOFA score and serum levels of IL-10 during the first week. In addition, we found higher serum levels of TNF- $\alpha$ in non-survivor as compared to survivor septic patients at days 4 and 8 of severe sepsis diagnosis.

Table 3 shows the correlations between serum levels of SP, TNF-alpha and IL-10, and SOFA score during the first week of severe sepsis. There were found a statistically significant negative correlation between serum SP levels and SOFA score at day 4 of severe sepsis diagnosis, and a trend of not statistically significant at days 1 and 8 . 
Table 1. Comparisons between non-survivor and survivor severe septic patients on demographic and clinical characteristics at the time of severe sepsis diagnosis.

\begin{tabular}{|c|c|c|c|}
\hline Characteristic & Non-Survivors $(n=104)$ & Survivors $(n=206)$ & $p$-Value \\
\hline Sex female $-n(\%)$ & $36(34.6)$ & $66(32.0)$ & 0.70 \\
\hline Ischemic heart disease $-n(\%)$ & $10(9.6)$ & $21(10.2)$ & 0.99 \\
\hline Diabetes mellitus— $n(\%)$ & $42(40.4)$ & $52(25.2)$ & 0.009 \\
\hline $\mathrm{COPD}-n(\%)$ & $13(12.5)$ & 28 (13.6) & 0.86 \\
\hline Chronic renal failure $-\mathrm{n}(\%)$ & 11 (10.6) & $12(5.8)$ & 0.17 \\
\hline SOFA score-median (p 25-75) & $11(9-14)$ & $9(7-11)$ & $<0.001$ \\
\hline Platelets $\left(\right.$ cells $\left./ \mathrm{mm}^{3}\right)$-median $\times 10^{3}(\mathrm{p} 25-75)$ & $133(68-225)$ & $197(131-271)$ & $<0.001$ \\
\hline $\mathrm{PaO}_{2} / \mathrm{FIO}_{2}$ ratio-median (p 25-75) & $169(103-240)$ & $180(123-270)$ & 0.17 \\
\hline Leukocytes $\left(\right.$ cells $\left./ \mathrm{mm}^{3}\right)$-median $\times 10^{3}(\mathrm{p} 25-75)$ & $14.9(6.8-20.4)$ & $14.4(9.1-18.9)$ & 0.84 \\
\hline Lactic acid (mmol/L)—median (p 25-75) & $3.56(1.60-6.00)$ & $2.00(1.15-3.50)$ & $<0.001$ \\
\hline INR-median (p 25-75) & $1.42(1.15-1.90)$ & $1.25(1.10-1.50)$ & 0.003 \\
\hline Creatinine (mg/dL)—-median (p 25-75) & $1.63(1.00-2.95)$ & $1.30(0.80-2.10)$ & 0.007 \\
\hline Bilirubin (mg/dL)-median (p 25-75) & $0.94(0.50-2.17)$ & $0.87(0.47-1.40)$ & 0.26 \\
\hline aPTT (seconds)—median (p 25-75) & $36(29-46)$ & $32(28-39)$ & 0.005 \\
\hline APACHE-II score-median ( $\mathrm{p}$ 25-75) & $23(19-28)$ & $19(15-23)$ & $<0.001$ \\
\hline Age-median years ( $\mathrm{p} 25-75)$ & $64(56-74)$ & $60(47-69)$ & 0.003 \\
\hline Bloodstream infection- $-n(\%)$ & $17(16.3)$ & $30(14.6)$ & 0.74 \\
\hline Empiric antimicrobial treatment adequate & & & 0.72 \\
\hline Unknown due to negative cultures- $n(\%)$ & 55 (52.9) & $105(51.0)$ & \\
\hline Adequate $-n(\%)$ & $42(40.4)$ & $83(40.3)$ & \\
\hline Inadequate $-n(\%)$ & $3(2.9)$ & $4(1.9)$ & \\
\hline Unknown due to antigenuria diagnosis- $n(\%)$ & $4(3.8)$ & $14(6.8)$ & \\
\hline \multicolumn{4}{|l|}{ Microorganism responsibles } \\
\hline Unknwon-n $(\%)$ & $55(52.9)$ & $105(51.0)$ & 0.81 \\
\hline Gram-positive- $n(\%)$ & $26(25.0)$ & $50(24.3)$ & 0.89 \\
\hline Gram-negative $-n(\%)$ & $23(22.1)$ & $51(24.8)$ & 0.67 \\
\hline Fungii- $n(\%)$ & $4(3.8)$ & $4(1.9)$ & 0.45 \\
\hline Anaerobe- $n(\%)$ & $1(1.0)$ & $2(1.0)$ & 0.99 \\
\hline Site of infection & & & 0.75 \\
\hline Respiratory- $n(\%)$ & $61(58.7)$ & $118(57.3)$ & \\
\hline Abdominal- $n(\%)$ & $26(25.0)$ & $58(28.2)$ & \\
\hline Neurological & $1(1.0)$ & $4(1.9)$ & \\
\hline Urinary-n $(\%)$ & $5(4.8)$ & $11(5.3)$ & \\
\hline Skin-n (\%) & $5(4.8)$ & $9(4.4)$ & \\
\hline Endocarditis-n $(\%)$ & $5(4.8)$ & $6(2.9)$ & \\
\hline Osteomyelitis & $1(0.9)$ & 0 & \\
\hline Substance $\mathrm{P}(\mathrm{pg} / \mathrm{mL})$-median $(\mathrm{p} 25-75)$ & $278(113-429)$ & $422(314-522)$ & $<0.001$ \\
\hline TNF- $\alpha(\mathrm{pg} / \mathrm{mL})-$ median $(\mathrm{p} 25-75)$ & $36(18-74)$ & $30(19-49)$ & 0.24 \\
\hline Interleukin-10 median $\mathrm{pg} / \mathrm{mL}$ ( $\mathrm{p} 25-75)$ & $38(8-118)$ & $10(5-37)$ & $<0.001$ \\
\hline
\end{tabular}

Table 2. Comparisons on evolution of serum levels of substance P, TNF- $\alpha$ and IL-10, and SOFA score during the first week of severe sepsis.

\begin{tabular}{|c|c|c|c|}
\hline Parameters-Median (p 25-75) & Nonsurvivors & Survivors & $p$ \\
\hline Day 1 & $(n=104)$ & $(n=206)$ & \\
\hline Substance P (pg/mL)—median (p 25-75) & $278(113-429)$ & $422(314-522)$ & $<0.001$ \\
\hline SOFA score-median (p 25-75) & $11(9-14)$ & $9(7-11)$ & $<0.001$ \\
\hline TNF- $\alpha$-median pg/mL (p 25-75) & $36(18-74)$ & $30(19-49)$ & 0.24 \\
\hline Interleukin-10 median pg/mL (p 25-75) & $38(8-118)$ & $10(5-37)$ & $<0.001$ \\
\hline Day 4 & $(n=65)$ & $(n=206)$ & \\
\hline Substance P (pg/mL)-median (p 25-75) & $162(117-199)$ & $292(201-380)$ & $<0.001$ \\
\hline SOFA score-median (p 25-75) & $10(7-15)$ & $6(3-10)$ & $<0.001$ \\
\hline TNF- $\alpha$-median pg/mL (p 25-75) & $35(26-49)$ & $22(14-32)$ & 0.001 \\
\hline Interleukin-10 median pg/mL (p 25-75) & $13(6-37)$ & $6(5-13)$ & $<0.001$ \\
\hline Day 8 & $(n=55)$ & $(n=2064)$ & \\
\hline Substance $P(\mathrm{pg} / \mathrm{mL})$-median ( $\mathrm{p} 25-75)$ & $124(107-202)$ & $242(175-299)$ & $<0.001$ \\
\hline SOFA score-median (p 25-75) & $10(6-13)$ & $4(1-7)$ & $<0.001$ \\
\hline TNF- $\alpha$-median pg/mL (p 25-75) & $26(15-48)$ & $17(12-29)$ & 0.04 \\
\hline Interleukin-10 median pg/mL (p 25-75) & $12(6-28)$ & $5(5-9)$ & 0.001 \\
\hline
\end{tabular}

p 25-75 = percentiles 25-75; SOFA = Sepsis-related Organ Failure Assessment score; TNF = tumor necrosis factor. 


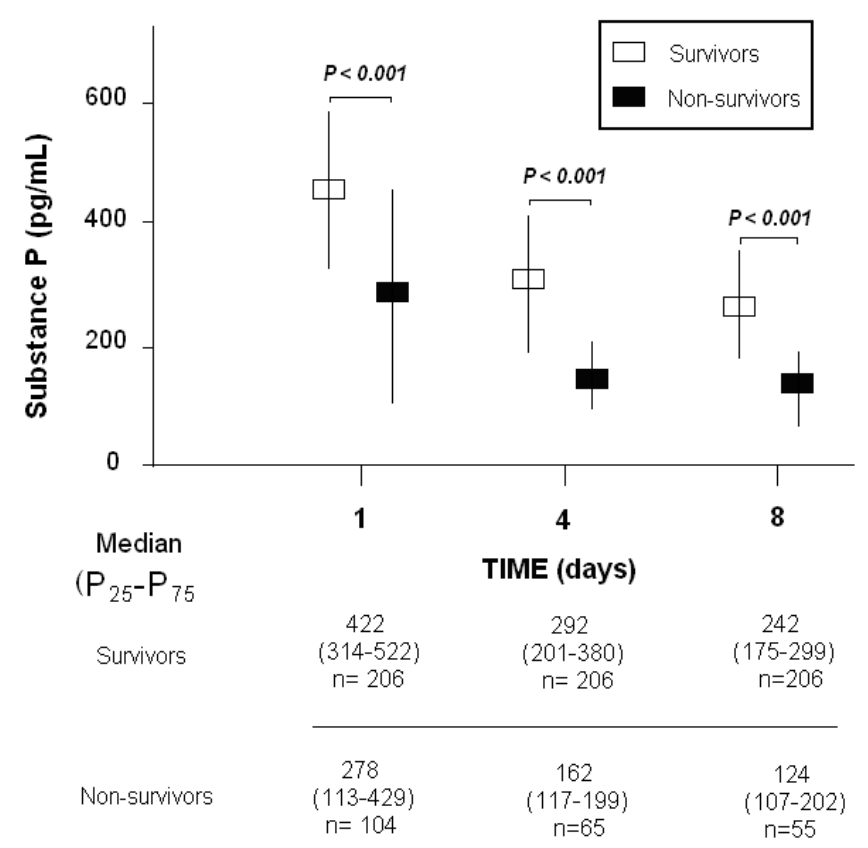

Figure 1. Serum substance P levels in survivor and non-survivor severe septic during the first week.

Table 3. Correlations between serum levels of substance P, TNF- $\alpha$ and IL-10, and SOFA score during the first week of severe sepsis.

\begin{tabular}{cccc}
\hline Header & Day $\mathbf{1}$ & Day $\mathbf{4}$ & Day 8 \\
\hline SOFA score & $R=-0.09 ; p=0.12$ & $R=-0.18 ; p=0.003$ & $R=-0.12 ; p=0.06$ \\
TNF- $\alpha(\mathrm{pg} / \mathrm{mL})$ & $R=0.11 ; p=0.13$ & $R=0.05 ; p=0.59$ & $R=0.08 ; p=0.42$ \\
Interleukin-10 $(\mathrm{pg} / \mathrm{mL})$ & $R=0.10 ; p=0.19$ & $R=0.03 ; p=0.72$ & $R=0.13 ; p=0.18$ \\
\hline
\end{tabular}

$\mathrm{TNF}=$ tumor necrosis factor; SOFA = Sepsis-related Organ Failure Assessment score. After Bonferroni correction only $p<0.005$ are statistically signifcant.

In Table 4 and Figure 2 appears ROC curve analyses for serum SP levels at days 1,4 , and 8 to predict 30-day mortality. We found that serum SP levels at day $1(p<0.001)$, day $4(p<0.001)$, and day $8(p<0.001)$ could predict 30-day mortality.
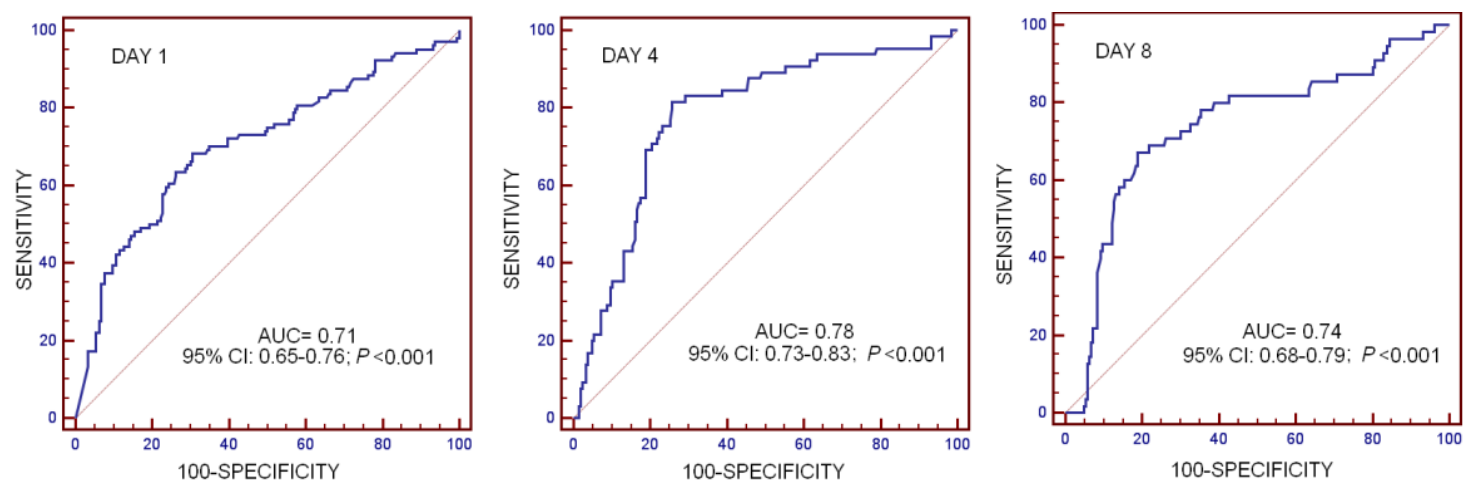

Figure 2. Curves of receiver operation characteristic analysis using serum Substance P levels at days 1, 4 , and 8 as a predictor of mortality at 30 days in severe septic patients. 
Table 4. Receiver operation characteristic analysis using serum Substance P levels at days 1, 4, and 8 as predictor of mortality at 30 days in severe septic patients: sensitivity, specificity, positive and negative likelihood ratios, positive and negative predicted values.

\begin{tabular}{cccc}
\hline Header & Day 1 & Day 4 & Day 8 \\
\hline Cut-off of Substance P $(\mathrm{pg} / \mathrm{mL})$ & $<339$ & $<203$ & $<148$ \\
\hline AUC, 95\% CI, and $p$-value & $0.71(0.65-0.76)$ & $0.78(0.73-0.83)$ & $0.74(0.68-0.79)$ \\
& $p<0.001$ & $p<0.001$ & $p<0.001$ \\
\hline Sensitivity and 95\% CI & $66.4(56.4-75.3)$ & $81.5(70.0-90.1)$ & $67.3(53.3-79.3)$ \\
Specificity and 95\% CI & $69.4(62.6-75.6)$ & $74.3(67.7-80.1)$ & $81.1(75.0-86.2)$ \\
Positive likelihood ratio and 95\% CI & $2.2(1.7-2.8)$ & $3.2(2.4-4.1)$ & $3.6(2.5-5.0)$ \\
Negative likelihood ratio and 95\% CI & $0.5(0.4-0.6)$ & $0.3(0.1-0.4)$ & $0.4(0.3-0.6)$ \\
Positive predicted value and 95\% CI & $52.3(43.4-61.0)$ & $50.0(40.1-59.9)$ & $48.7(37.0-60.4)$ \\
Negative predicted value and 95\% CI & $80.3(73.7-85.9)$ & $92.7(87.6-96.2)$ & $90.3(85.1-94.1)$ \\
\hline
\end{tabular}

AUC: area under curve; CI: confidence intervals.

Table 5 shows multiple logistic regression analyses, and we found an association between 30-day mortality and serum SP levels at days 1,4 , and $8(p<0.001)$ controlling for SOFA score, diabetes mellitus, age, and lactic acid levels.

Table 5. Multiple logistic regression analyses to predict mortality at 30 days.

\begin{tabular}{|c|c|c|c|}
\hline Header & Hazard Ratio & 95\% Confidence Interval & $p$-Value \\
\hline \multicolumn{4}{|l|}{ Model: Mortality estimated at day 1} \\
\hline SP levels $<339 \mathrm{pg} / \mathrm{mL}$ at day 1 & 4.296 & $2.470-7.471$ & $<0.001$ \\
\hline SOFA at day 1 & 1.165 & $1.070-1.267$ & $<0.001$ \\
\hline Lactic acid (mmol/L) at day 1 & 1.110 & $1.008-1.223$ & 0.03 \\
\hline Diabetes Mellitus & 1.789 & $0.989-3.237$ & 0.055 \\
\hline Age (years) & 1.022 & $1.002-1.042$ & 0.03 \\
\hline \multicolumn{4}{|l|}{ Model: Mortality estimated at day 4} \\
\hline SP levels $<203 \mathrm{pg} / \mathrm{mL}$ at day 4 & 14.619 & $6.304-33.900$ & $<0.001$ \\
\hline SOFA at day 4 & 1.118 & $1.017-1.229$ & 0.02 \\
\hline Lactic acid (mmol/L) at day 4 & 1.652 & $1.241-2.198$ & 0.001 \\
\hline Diabetes Mellitus & 2.001 & $0.917-4.365$ & 0.08 \\
\hline Age (years) & 1.027 & $1.001-1.054$ & 0.04 \\
\hline \multicolumn{4}{|l|}{ Model: Mortality estimated at day 8} \\
\hline SP levels $<148 \mathrm{pg} / \mathrm{mL}$ at day 8 & 6.003 & $2.711-13.290$ & $<0.001$ \\
\hline SOFA at day 8 & 1.212 & $1.111-1.323$ & $<0.001$ \\
\hline Lactic acid (mmol/L) at day 8 & 1.557 & $0.933-2.599$ & 0.09 \\
\hline Diabetes Mellitus & 1.669 & $0.734-3.793$ & 0.22 \\
\hline Age (years) & 1.026 & $0.997-1.056$ & 0.08 \\
\hline
\end{tabular}

$\mathrm{SP}=$ substance P; SOFA = Sepsis-related Organ Failure Assessment.

In Figure 3 appears Kaplan-Meier survival analysis at days 1, 4, and 8 of severe sepsis diagnosis according to different serum SP levels. We found a higher risk of death risk in patients with serum SP levels $<339 \mathrm{pg} / \mathrm{mL}$ at the time of severe sepsis diagnosis than in patients with higher concentrations (Hazard Ratio $=3.5 ; 95 \%$ CI $=2.35-5.18 ; p<0.001$ ), in patients with serum SP levels $<203 \mathrm{pg} / \mathrm{mL}$ at day 4 , and in patients with serum SP levels $<148 \mathrm{pg} / \mathrm{mL}$ at day 8 . 



Figure 3. Survival curves at 30 days using serum substance P levels higher or lower than $339 \mathrm{pg} / \mathrm{mL}$.

\section{Discussion}

To our knowledge, the current study is the largest reporting data on circulating SP levels from septic patients. The most interesting findings of our study were that there is an association between serum SP levels during the first week and sepsis mortality, and that serum SP levels during the first week could be used as a biomarker of sepsis mortality.

In a previous study [26], we found higher serum SP levels at moment of severe sepsis diagnosis in survivor than in non-survivor severe septic patients; thus, a novel finding of our current study was that survivor severe septic patients showed persistently higher serum SP levels during the first week than non-survivors. We have not determined serum SP levels in healthy controls; however, the serum SP levels found in our survivor and non-survivor severe septic patients were lower than those described from healthy volunteers in the data set of kit used for the assay (mean 628, and range 402-1576 pg/mL). Our findings are in accordance with those from the study by Arnalic et al. with 42 septic patients, in which were found lower plasma SP concentrations in septic patients compared to healthy controls [24]; and with those from the study by Jacob et al., in which was found lower SP expression in small bowel from patients with than without peritonitis [25]. On the other hand, our findings contradict with those of the study by Beer et al. with 61 septic patients, in which were found higher serum SP concentrations in septic patients compared to healthy controls and in non-survivor compared to survivor patients during the final phase of sepsis [23].

In our previous study, an association was found between sepsis mortality and serum SP levels at moment of severe sepsis diagnosis [26]; then, the association between sepsis mortality and serum SP levels during the first week found in our current study is another new point. In addition, the capacity of serum SP levels at moment of severe sepsis diagnosis to predict 30-day mortality was found in our previous study [26]; then, another novel finding of our current study was that serum SP levels at days 4 and 8 also could predict 30-day mortality.

The role of SP in sepsis remains unclear. On the one hand, in some studies was found that SP could play a role in the inflammatory response to sepsis by the release of pro-inflammatory cytokines as IL-1, IL-6, and TNF- $\alpha$ [13-16]. On the other hand, in other studies it has been found that the intravenous administration of SP in animal models with spinal cord injury decreased TNF-alpha, IL-6, and iNOS, and increasied IL-10 $[17,18]$. However, in our study we found no correlation between serum levels of SP, TNF- $\alpha$, and IL-10. Besides, SP could pay a role in the phagocytosis; and therefore, in the microorganism clearance and infection control [19-22]. In a study by Verdrengh et al., Staphylococcus aureus was administered intravenously to neurokinin-1 receptor (NK-1R) knockout mice (without receptors to substance P) and control mice, and found that NK-1R knockout mice compared to control mice showed fewer phagocytose bacteria capacity of macrophages, higher burden of staphylococci in 
the kidneys, more severe arthritic lesions with more severe synovitis and cartilage/bone destruction, and higher 11-day post-infection mortality rate [19]. In a study by Yang et al. it was found that the administration of NK-1R antagonist reduces pulmonar bacterial clearance and survival in mice undergoing to traumatic brain injury and intrapulmonary infection with Pseudomonas aeruginosa [20]. In a study by Kincy et al., Salmonella was administered orally to mice previously or not treated with an NK-1R antagonist and there was found that mice pretreated with the NK-1R antagonist compared to mice control developed more severe salmonellosis and had lower survival rates [21]. In a study by Lighvani et al., it was found that mice pretrated with a NK-1R antagonist before a corneal infection with Pseudomonas aeruginosa showed more severe disease with higher corneal perforation rate that control mice [22].

We think that the finding of our study about that non-survivor severe septic patients showed persistently lower serum SP levels during the first week than survivors could represents that non-survivor patients showed a lower phagocytosis capacity and microorganism clearance. Besides, according to the findings of those studies in animal models with SP administration, it is possible that non-survivor patients showed a lower inflammatory state. More research could be interesting to confirm our findings due to that in that case, serum SP levels determination could be used in clinical practice to estimate the prognosis of these patients, and one new approach in the research for the treatment of these patients could be suggested.

Our study had some limitations. First, we have not determined serum SP levels in healthy volunteers, septic patients without criteria of severe sepsis, and other critically ill patients; however, the objective of our study was not to determine whether severe sepsis influenced serum SP levels, but rather was to determine whether there is an association between serum SP levels during the first week and sepsis mortality, and whether serum SP levels during the first week could be used as a biomarker of sepsis mortality. In addition, serum SP levels found in our survivor and non-survivor severe septic patients were lower than those described from healthy volunteers in the data set of kit used for the assay (and were lower in our non-survivor than in survivor septic patients). Second, the determination of serum substance $P$ levels during more days of follow-up could be interesting. Third, we have not evaluated the phagocytosis capacity in survivor and non-survivor septic patients. Fourth, we have not determined circulating levels of interleukin- 6 and c-reactive protein. Fifth, we did not calculate sample size in our study although was enough to find that there is an association between serum SP levels during the first week and sepsis mortality, and that serum SP levels during the first week could be used as biomarker of sepsis mortality. Sixth, there is a new sepsis definition [27]; however, we used the same sepsis definition in both works of our team [28].

\section{Methods}

\subsection{Design and Subjects}

A prospective, multicenter, observational study was carried out with 321 severe septic patients in Intensive Care Units from six Spanish hospitals: Clínico Universitario de Valencia (Valencia), Insular (Las Palmas de Gran Canaria), San Jorge (Huesca), Universitario de Canarias (La Laguna. Tenerife), Universitario Dr. Negrín (Las Palmas de Gran Canaria), and Universitario Nuestra Señora de Candelaria (Santa Cruz de Tenerife). The study was approved by the Institutional Ethic Review Boards of the six hospitals. Patients or family members signed the informed consent to participate in the study. The study adheres to the World Medical Association Declaration of Helsinki regarding ethical conduct of research involving human subjects.

The criterion for inclusion was severe sepsis according to the International Sepsis Definitions Conference [28]. Criteria for exclusion were: pregnancy, lactation, age $<18$ years, steroid, immunosuppressive or radiation therapy, human immunodeficiency virus (HIV), white blood cell count $<1000 / \mu \mathrm{L}$, solid or hematological tumor. 
Previously, we determined other circulating biomarkers in some of those patients [29-32]. In a previous work, we analyzed serum SP levels in 238 severe septic patients at the time of severe sepsis diagnosis (within $2 \mathrm{~h}$ of the diagnosis of severe sepsis) [26]. In the current work, we have analyzed serum SP levels in 310 severe septic patients during the first week of severe sepsis.

The end-point of the study was 30-day mortality. We also collected the following variables: sex, age, ischemic heart disease, diabetes mellitus, chronic obstructive pulmonary disease (COPD), chronic renal failure (defined as glomerular filtration rate lower than $60 \mathrm{~mL} / \mathrm{min}$ per $1.73 \mathrm{~m}^{2}$ ), Sepsis-related Organ Failure Assessment [SOFA] score [33], platelets, pressure of arterial oxygen/fraction inspired of oxygen $\left(\mathrm{PaO}_{2} / \mathrm{FIO}_{2}\right)$, leukocytes, lactic acid, international normalized ratio (INR), creatinine, bilirubin, activated partial thromboplastin time (aPTT), Acute Physiology and Chronic Health Evaluation II (APACHE II) score [34], bloodstream infection, empiric antimicrobial treatment, microorganism responsible, and site of infection.

\subsection{Determination of Serum Concentrations of SP, Tumor Necrosis Factor (TNF)- $\alpha$, and Interleukin (IL)-10}

Blood samples were collected from patients on day 1,4 , and 8 of severe sepsis diagnosis to determine serum concentrations of SP, TNF-alpha, and IL-10. Blood samples were deposited in serum separator tubes, then blood samples were allowed to clot for $10 \mathrm{~min}$ at room temperature, later were centrifuged at $1000 \times g$ for $15 \mathrm{~min}$ and the supernatant was immediately stored in aliquot at $-80^{\circ} \mathrm{C}$ until assayed to the end of the recruitment process. Samples were transported between different locations in refrigerated boxes with dry ice. The determinations of serum concentrations were performed at the end of the recruitment process in the Laboratory Department of the Hospital Universitario de Canarias (La Laguna, Tenerife, Spain) blinded to clinical data.

Serum SP levels were assayed by specific Enzyme Linked Immunosorbent Assay (ELISA) according to the manufacturer's instructions (R\&D Systems, Abingdon, UK). Serum concentrations of TNF-alpha and IL-10 were determined using solid-phase chemiluminescent immunometric assays using Immulite ${ }^{\circledR}$ (Siemens Healthcare Diagnostics Products, Llanberis, UK). The intra-assay coefficient of variation (CV) were $9 \%, 3.6 \%$, and $9.9 \%$, respectively. The inter-assay CV were $15 \%, 6.5 \%$, and $9.9 \%$, respectively. The detection limits for the assays were $25,1.7$, and $1.0 \mathrm{pg} / \mathrm{mL}$, respectively.

\subsection{Statistical Methods}

We reported categorical variables as frequencies (and percentages), and continuous variables as medians (and interquartile ranges); and we used chi-square test and Mann-Whitney U test, respectively, for the comparison between patient groups.

We did receiver operating characteristic (ROC) analyses using serum SP levels at days 1, 4, and 8 as prognostic variables; and survival at 30 days as classification variable. Youden J index was used to select the optimal prognostic cut-off value of serum SP levels for days 1, 4, and 8 . We made multiple logistic regression analyses to test the association between 30-day mortality and serum SP levels at days 1, 4, and 8, controlling for SOFA score, lactic acid levels, diabetes mellitus, and age. To measure the clinical impact of prognostic variables were calculated hazard ratio and its $95 \%$ confidence intervals (CI).

We analyzed 30-day survival using Kaplan-Meier method; and we used serum SP levels higher or lower than $339 \mathrm{pg} / \mathrm{mL}$ at day $1,203 \mathrm{pg} / \mathrm{mL}$ at day 4 , and $148 \mathrm{pg} / \mathrm{mL}$ at day 8 as the independent variables, survival at 30 days as the dependent variable, and log-rank test for the comparison. We used those serum SP levels values $(339,203$, and $148 \mathrm{pg} / \mathrm{mL}$ ) because are the optimal prognostic cut-off values according to Youden $\mathrm{J}$ index calculations.

Spearman's rank coefficient was used to determine the correlation between serum levels of SP, TNF- $\alpha$ and IL-10, and SOFA score at days 1,4 , and 8. Values of $p$ less than 0.05 were considered statistically significant; besides, Bonferroni correction was used in multiple comparisons. We performed statistical analyses by SPSS 17.0 (SPSS Inc., Chicago, IL, USA) and NCSS 2000 (Kaysville, UT, USA). 


\section{Conclusions}

The current study is the largest reporting data on circulating SP levels from septic patients. The most interesting findings of our study were that there is an association between serum SP levels during the first week and sepsis mortality, and that serum SP levels during the first week could be used as biomarker of sepsis mortality based on findings in our population.

Acknowledgments: This study was supported by a grant from Instituto de Salud Carlos III (INT16/00165) (Madrid, Spain) and co-financed by Fondo Europeo de Desarrollo Regional (FEDER). The funding has not affected the study design; the collection, analysis, and interpretation of data; the writing of the manuscript; or the decision to submit the manuscript for publication.

Author Contributions: Leonardo Lorente conceived, designed, and coordinated the study; participated in acquisition and interpretation of data; and drafted the manuscript. María M. Martín, José Ferreres, Jordi Solé-Violán, Lorenzo Labarta, and César Díaz participated in acquisition of data. Antonia Pérez-Cejas participated in blood determination levels. Alejandro Jiménez participated in the interpretation of data. All authors revised the manuscript critically for important intellectual content and made the final approval of the version to be published.

Conflicts of Interest: The authors declare that they have no competing interests.

\section{Abbreviations}

$\begin{array}{ll}\text { APACHE } & \text { Acute physiology and chronic health evaluation } \\ \text { aPTT } & \text { Activated partial thromboplastin time } \\ \text { COPD } & \text { Chronic obstructive pulmonary disease } \\ \text { FIO2 } & \text { Fraction inspired oxygen } \\ \mathrm{INR} & \text { International normalized ratio } \\ \mathrm{ICU} & \text { Intensive care unit } \\ \mathrm{PaO}_{2} & \text { Pressure of arterial oxygen } \\ \mathrm{TNF} & \text { Tumor necrosis factor } \\ \text { SOFA } & \text { Sepsis-related organ failure assessment score } \\ \text { SP } & \text { Substance P }\end{array}$

\section{References}

1. Angus, D.C.; Linde-Zwirble, W.T.; Lidicker, J.; Clermont, G.; Carcillo, J.; et al. Epidemiology of severe sepsis in the United States: analysis of incidence, outcome, and associated costs of care. Crit. Care Med. 2001, 29, 1303-1310. [CrossRef] [PubMed]

2. Vincent, J.L.; Sakr, Y.; Sprung, C.L.; Ranieri, V.M.; Reinhart, K.M.; Gerlach, H.; Moreno, R.; Carlet, J.; Le Gall, J.R.; Payen, D. Sepsis Occurrence in Acutely Ill Patients Investigators. Sepsis in European intensive care units: Results of the SOAP study. Crit. Care Med. 2006, 34, 344-353. [CrossRef] [PubMed]

3. Maggi, C.A. The effects of tachykinins on inflammatory and immune cells. Regul. Pept. 1997, 70, 75-90. [CrossRef]

4. Barnes, P.J. Neurogenic inflammation in the airways. Respir. Physiol. 2001, 125, 145-154. [CrossRef]

5. Almeida, T.A.; Rojo, J.; Nieto, P.M.; Pinto, F.M.; Hernandez, M.; Martín, J.D.; Candenas, M.L. Tachykinins and tachykinin receptors: Structure and activity relationships. Curr. Med. Chem. 2004, 11, 2045-2081. [CrossRef] [PubMed]

6. Pennefather, J.N.; Lecci, A.; Candenas, M.L.; Patak, E.; Pinto, F.M.; Maggi, C.A. Tachykinins and tachykinin receptors: A growing family. Life Sci. 2004, 74, 1445-1463. [CrossRef] [PubMed]

7. Groneberg, D.A.; Quarcoo, D.; Frossard, N.; Fischer, A. Neurogenic mechanisms in bronchial inflammatory diseases. Allergy 2004, 59, 1139-1152. [CrossRef] [PubMed]

8. Satake, H.; Kawada, T. Overview of the Primary Structure, Tissue-Distribution, and Functions of Tachykinins and their Receptors. Curr. Drug Targets 2006, 7, 963-974. [CrossRef] [PubMed]

9. De Swert, K.O.; Joos, G.F. Extending the understanding of sensory neuropeptides. Eur. J. Pharmacol. 2006, 533, 171-181. [CrossRef] [PubMed]

10. Bodkin, J.V.; Fernandes, E.S. TRPV1 and SP: Key elements for sepsis outcome? Br. J. Pharmacol. 2013, 170, 1279-1292. [CrossRef] [PubMed] 
11. Steinhoff, M.S.; von Mentzer, B.; Geppetti, P.; Pothoulakis, C.; Bunnett, N.W. Tachykinins and their receptors: Contributions to physiological control and the mechanisms of disease. Physiol. Rev. 2014, 94, 265-301. [CrossRef] [PubMed]

12. Mashaghi, A.; Marmalidou, A.; Tehrani, M.; Grace, P.M.; Pothoulakis, C.; Dana, R. Neuropeptide substance P and the immune response. Cell Mol. Life Sci. 2016, 73, 4249-4264. [CrossRef] [PubMed]

13. Lotz, M.; Vaughan, J.H.; Carson, D.A. Effect of neuropeptides on production of inflammatory cytokines by human monocytes. Science 1988, 241, 1218-1221. [CrossRef] [PubMed]

14. Laurenzi, M.A.; Persson, M.A.; Dalsgaard, C.J.; Haegerstrand, A. The neuropeptide substance P stimulates production of interleukin 1 in human blood monocytes: Activated cells are preferentially influenced by the neuropeptide. Scand. J. Immunol. 1990, 31, 529-533. [CrossRef] [PubMed]

15. Ansel, J.C.; Brown, J.R.; Payan, D.G.; Brown, M.A. Substance P selectively activates TNF- $\alpha$ gene expression in murine mast cells. J. Immunol. 1993, 150, 4478-4485. [PubMed]

16. Yamaguchi, M.; Kojima, T.; Kanekawa, M.; Aihara, N.; Nogimura, A.; Kasai, K. Neuropeptides stimulate production of interleukin-1b, interleukin-6, and tumor necrosis factor- $\alpha$ in human dental pulp cells. Inflamm. Res. 2004, 53, 199-204. [CrossRef] [PubMed]

17. Jiang, M.H.; Chung, E.; Chi, G.F.; Ahn, W.; Lim, J.E.; Hong, H.S.; Kim, D.W.; Choi, H.; Kim, J.; Son, Y. Substance P induces M2-type macrophages after spinal cord injury. Neuroreport 2012, 23, 786-792. [CrossRef] [PubMed]

18. Jiang, M.H.; Lim, J.E.; Chi, G.F.; Ahn, W.; Zhang, M.; Chung, E.; Son, Y. Substance P reduces apoptotic cell death possibly by modulating the immune response at the early stage after spinal cord injury. Neuroreport 2013, 24, 846-851. [CrossRef] [PubMed]

19. Verdrengh, M.; Tarkowski, A. The impact of substance P signalling on the development of experimental staphylococcal sepsis and arthritis. Scand. J. Immunol. 2008, 67, 253-259. [CrossRef] [PubMed]

20. Yang, S.; Stepien, D.; Hanseman, D.; Robinson, B.; Goodman, M.D.; Pritts, T.A.; Caldwell, C.C.; Remick, D.G.; Lentsch, A.B. Substance P mediates reduced pneumonia rates after traumatic brain injury. Crit. Care Med. 2014, 42, 2092-2100. [CrossRef] [PubMed]

21. Kincy-Cain, T.; Bost, K.L. Increased susceptibility of mice to Salmonella infection following in vivo treatment with the substance P antagonist, spantide II. J. Immunol. 1996, 157, 255-264. [PubMed]

22. Lighvani, S.; Huang, X.; Trivedi, P.P.; Swanborg, R.H.; Hazlett, L.D. Substance P regulates natural killer cell interferon-gamma production and resistance to Pseudomonas aeruginosa infection. Eur. J. Immunol. 2005, 35, 1567-1575. [CrossRef] [PubMed]

23. Beer, S.; Weighardt, H.; Emmanuilidis, K.; Harzenetter, M.D.; Matevossian, E.; Heidecke, C.D.; Bartels, H.; Siewert, J.R.; Holzmann, B. Systemic neuropeptide levels as predictive indicators for lethal outcome in patients with postoperativesepsis. Crit. Care Med. 2002, 30, 1794-1798. [CrossRef] [PubMed]

24. Arnalich, F.; Sánchez, J.F.; Martínez, M.; Jiménez, M.; López, J.; Vázquez, J.J.; Hernanz, A. Changes in plasma concentrations of vasoactive neuropeptides in patients with sepsis and septic shock. Life Sci. 1995, 56, 75-81. [CrossRef]

25. Jacob, P.; Mueller, M.H.; Hahn, J.; Wolk, I.; Mayer, P.; Nagele, U.; Hennenlotter, J.; Stenzl, A.; Konigsrainer, A.; Glatzle, J. Alterations of neuropeptides in the human gut during peritonitis. Langenbecks Arch. Surg. 2007, 392, 267-271. [CrossRef] [PubMed]

26. Lorente, L.; Martín, M.M.; Almeida, A.; Hernández, M.; Ferreres, J.; Solé-Violán, J.; Labarta, L.; Díaz, C.; Jiménez, A. Association between serum substance P levels and mortality in patients with severe sepsis. J. Crit. Care 2015, 30, 924-928. [CrossRef] [PubMed]

27. Singer, M.; Deutschman, C.S.; Seymour, C.W.; Shankar-Hari, M.; Annane, D.; Bauer, M.; Bellomo, R.; Bernard, G.R.; Chiche, J.D.; Coopersmith, C.M.; et al. The Third International Consensus Definitions for Sepsis and Septic Shock (Sepsis-3). JAMA 2016, 315, 801-810.

28. Levy, M.M.; Fink, M.P.; Marshall, J.C.; Abraham, E.; Angus, D.; Cook, D.; Cohen, J.; Opal, S.M.; Vincent, J.L.; Ramsay, G. International Sepsis Definitions Conference: 2001 SCCM/ ESICM/ ACCP/ ATS/ SIS International Sepsis Definitions Conference. Intensive Care Med. 2003, 29, 530-538. [CrossRef] [PubMed]

29. Lorente, L.; Martín, M.M.; Abreu-González, P.; Domínguez-Rodriguez, A.; Labarta, L.; Díaz, C.; Solé-Violán, J.; Ferreres, J.; Cabrera, J.; Igeño, J.C.; et al. Sustained high serum malondialdehyde levels are associated with severity and mortality in septic patients. Crit. Care 2013, 17, R290. [CrossRef] [PubMed] 
30. Lorente, L.; Martín, M.M.; Solé-Violán, J.; Blanquer, J.; Labarta, L.; Díaz, C.; Borreguero-León, J.M.; Orbe, J.; Rodríguez, J.A.; Jiménez, A.; et al. Association of sepsis-related mortality with early increase of TIMP-1/MMP-9 ratio. PLoS ONE 2014, 9, e94318. [CrossRef] [PubMed]

31. Lorente, L.; Martín, M.M.; López-Gallardo, E.; Blanquer, J.; Solé-Violán, J.; Labarta, L.; Díaz, C.; Jiménez, A.; Montoya, J.; Ruiz-Pesini, E. Decrease of oxidative phosphorylation system function in severe septic patients. J. Crit. Care. 2015, 30, 935-939. [CrossRef] [PubMed]

32. Lorente, L.; Martín, M.M.; Pérez-Cejas, A.; López, R.O.; Ferreres, J.; Solé-Violán, J.; Labarta, L.; Díaz, C.; Palmero, S.; Buitrago, M.; et al. Higher serum caspase-cleaved cytokeratin-18 levels during the first week of sepsis diagnosis in non-survivor patients. Clin. Chem. Lab. Med. 2017. [CrossRef] [PubMed]

33. Vincent, J.L.; Moreno, R.; Takala, J.; Willatts, S.; de Mendonça, A.; Bruining, H.; Reinhart, C.K.; Suter, P.M.; Thijs, L.G. The SOFA (Sepsis-related Organ Failure Assessment) score to describe organ dysfunction/failure. Intensive Care Med. 1996, 22, 707-710. [CrossRef] [PubMed]

34. Knaus, W.A.; Draper, E.A.; Wagner, D.P.; Zimmerman, J.E. APACHE II: A severity of disease classification system. Crit. Care Med. 1985, 13, 818-829. [CrossRef] [PubMed]

(C) 2017 by the authors. Licensee MDPI, Basel, Switzerland. This article is an open access article distributed under the terms and conditions of the Creative Commons Attribution (CC BY) license (http://creativecommons.org/licenses/by/4.0/). 